\title{
RETÓRICA DE UMA BIOGRAFIA: PADRE ANTONIO VIEIRA POR JOÃO LÚCIO DE AZEVEDO
}

\author{
Alcir Pécora \\ Universidade Estadual de Campinas (UNICAMP) \\ alcirpecora@gmail.com
}

RESUMO / ABSTRACT

Em larga medida, a imagem do Padre Vieira (1608-1697), que se faz ainda hoje, como um homem dividido entre atuações muito diversas, ambicioso politicamente, temperamental, contraditório, movido a quimeras, seduzido um pouco por sua própria lábia, mas também sempre um caráter grandioso, valente, determinado... deve-se à biografia do padre de autoria do historiador português João Lúcio de Azevedo (1855-1933). Esta imagem se sedimentou a tal ponto, que é difícil imaginar outras interpretações convincentes para a sua atuação. Novas biografias não têm feito mais que glosar esses mesmos termos. De qualquer modo, quando, em vários trabalhos, procurei me opor a certas divisões periodológicas e psicologizantes que pareciam determinar grande parte das leituras da obra de Vieira, era sobretudo essa biografia que tinha de enfrentar. Quais os procedimentos narrativos que a tornam tão especialmente convincente? -- esta a pergunta que tento responder em meu texto.

Palavras chaves: Padre Antonio Vieira; João Lúcio de Azevedo; biografia; historiografia luso-brasileira; história positivista; retrato; personificação.

To a large extent, the fact that Father Antonio Vieira (1608-1697) is still seen as a man who was divided among very diverse actions, politically ambitious, temperamental, contradictory, driven by chimeras, slightly attracted by his own eloquence, but at the same time as somebody with a great character; brave and decided, is due to father Vieira's biography written by the Portuguese historian João Lúcio de Azevedo (1855-1933). This image has been so firmly settled that it is now difficult to think of different convincing interpretations of father Vieira's actions. New biographies have done nothing but provide more information about the same terms. As a matter of fact, when I tried, in several works, to oppose to certain periodological and psychologizing divisions that seemed to determine a large part of Vieira's readings, it 
was especially that biography what I had to face. What narrative procedures make Vieira's biography so particularly convincing? That is the question that I try to answer in this article.

KEY WORDS: biography, Luso-Brazilian historiography, positivist history, portrait, personification.

Em larga medida, a imagem do Padre Vieira, que se faz ainda hoje, como um homem dividido entre atuações muito diversas, ambicioso politicamente, temperamental, contraditório, movido a quimeras, seduzido um pouco por sua própria lábia, mas também sempre um caráter grandioso, valente, pertinaz, deve-se às páginas eletrizantes da História de Antônio Vieira, do historiador português João Lúcio de Azevedo (1855-1933). Para o bem e para o mal, esta imagem se sedimentou a tal ponto, senão no imaginário corrente, ao menos entre os admiradores e estudiosos do Padre, que é difícil imaginar outras interpretações para a sua vida.

Quando, há mais de vinte anos, em minha tese de doutoramento, procurei me opor a certas divisões periodológicas e psicologizantes que pareciam determinar grande parte das leituras da obra de Vieira, era sobretudo a biografia do jesuíta feita por João Lúcio que tinha de enfrentar. Por exemplo, gostaria de poder evitar imagens como as de "revoltado", que reduz a grandeza de sua passagem por Roma, ou de "vencido", que dá tintura melancólica ao seu período final na Bahia, que se estende por mais de quinze anos bem animados.

Certamente, havemos todos de ser vencidos pela morte, mas caracterizar Vieira como "vencido", à maneira da geração 70, em Portugal, ou ter uma visão patética de seu período final na Bahia, não é, a meu ver, a única interpretação verossímil de um homem que, até o fim dos seus dias, ainda escreve diariamente a amigos e autoridades, além de palpitar sobre todo tipo de assunto, como sabemos pelo próprio trabalho de Azevedo, que, não por acaso, também é o principal editor das cartas do jesuíta.

Como disse, penso que é mais do que hora de articular a totalidade de sua atuação, como pregador, escritor, teólogo, missionário, valido, conselheiro político, diplomata, analista de profecias e especulador de prodígios de vária ordem, de forma menos etapista. Nada que for feito nesse sentido, entretanto, pode ignorar o tremendo êxito da narrativa biográfica de Vieira produzida por João Lúcio de Azevedo. Afora o interesse que o livro tem para o debate historiográfico do início do século XX, no qual a naturalização positivista dos fatos começa a ser criticada em nome de aspectos filológicos e interpretativos que consideram com maior cuidado o lugar e a autoridade das fontes, também 
não há como desdenhar a arquitetura documental e analítica montada por ele para dar um retrato verossímil do biografado.

O que mais espanta, contudo, é que, ao mesmo tempo em que falamos deste incontornável Antônio Vieira construído vastamente por João Lúcio de Azevedo, o livro responsável por essa construção simplesmente não havia sido editado no Brasil até 2008, isto é, 90 anos depois de ter sido editado em Portugal! Quer dizer, a força de sua invenção se impôs por meio de leituras intermediárias, pela vulgarização das suas palavras originais, nem sempre atribuídas limpamente a seu criador. Não são sequer muitos, no Brasil, os que têm lembrança de sua importância como historiador, mesmo sem falar da biografia de Vieira. Sérgio Buarque de Holanda está entre os que o leram e souberam reconhecer sua contribuição para a historiografia portuguesa e brasileira. Por exemplo, em "O Pensamento Histórico no Brasil nos últimos 50 anos", editado originalmente no Correio da Manhã, em 15 de julho de 1951, Sérgio afirma:

Sobre o extremo norte existia, desde 1901, o importante trabalho do historiador português João Lúcio de Azevedo consagrado aos Jesuitas do Grão-Pará. Ao mesmo historiador devemos uma história do padre Vieira, impressa pela primeira vez em 1918, e também uma edição nova e enriquecida das cartas de Vieira, que vieram enriquecer consideravelmente nosso conhecimento da vida e obra do grande pregador (Buarque de Holanda-Perspectivas).

Nessas circunstâncias, aproveito a oportunidade deste fórum, para me ocupar justamente dessa História de Antônio Vieira, cuja primeira edição, em dois volumes, saída em 1918-20, foi ainda corrigida pela segunda de 1931. Antes, permitam-me apenas uma breve apresentação do biógrafo, sem que eu mesmo tenha qualquer pretensão biográfica. Vão aqui apenas algumas linhas gerais a seu respeito.

No Dicionário de História de Portugal, dirigido por Joel Serrão, consta, no primeiro volume, o verbete "Azevedo, João Lúcio de (1855-1933)", de autoria de Maria Antonieta Soares de Azevedo, do Instituto de Odivelas. Anota ela que o biógrafo de Vieira nasceu em Sintra, a 16 de abril de 1855, fez estudos elementares em Mafra e se diplomou em Comércio, em Lisboa. 
Aos 18 anos, teria emigrado para o Brasil, fixando-se em Belém do Pará. De empregado numa livraria, tornou-se seu proprietário, tendo feito fortuna no negócio. Ao buscar explicação plausível para o salto de próspero comerciante a historiador de bom coturno, a autora combina sociologia de meio cultural com psicologia da personalidade inata, e escreve:

Em contacto com o mundo dos livros e levado por natural curiosidade, aumentou a sua cultura e depressa manifestou o pendor para os temas histórico (264).

Se não chega a ser muito elucidativo, ao menos não atrapalha os fatos, pois, em 1893, ainda em Belém, João Lúcio já é autor de vários trabalhos historiográficos, reunidos e publicados num volume intitulado Estudos da História Paraense. Segundo a mesma Maria Antonieta, a obra garantiu o seu ingresso no Instituto Histórico e Geográfico Brasileiro, no ano seguinte, "por proposta assinada por José Veríssimo, José Luís Alves e T. Alencar Araripe".

Em 1900, João Lúcio regressa à Europa e passa alguns anos em Paris, antes de retornar definitivamente a Portugal e dedicar-se exclusivamente aos estudos historiográficos. Ingressou na Sociedade Portuguesa de Estudos Históricos, fundada em 1911, por Fidelino de Figueiredo, a qual, entre outros nomes de historiadores conhecidos, reunia Braamcamp Freire, Edgar Prestage e Oliveira Lima. Segundo anota ainda Maria Antonieta, João Lúcio deve ser visto como "um historiador luso-brasileiro", devido ao "objecto da maior parte dos seus estudos". Além disso, diz ela:

Ao Brasil o uniam ainda laços afectivos. A José Veríssimo o ligou sempre grande amizade e por ele se estabeleceram também as suas amistosas relações com Capistrano de Abreu (264).

Deixando a relação com José Veríssimo para outro momento, assim como o ponto historiograficamente ainda mais relevante da amizade com Capistrano, convém destacar três juízos emitidos por Maria Antonieta de Azevedo a propósito da atuação historiográfica de João Lúcio. Dois positivos: o de que a ele se deveu a "primeira e talvez, ainda única, história econômica" (265) de Portugal, -o Épocas de Portugal Econômico, de 1929-, e o de ter ele abordado "pela primeira vez, temas de grande interesse para a história de Portugal, abrindo, como pioneiro, o caminho a futuras e proveitosas investigações" (265). 
A ler com má vontade os elogios, ambos acentuam mais o pioneirismo dos seus trabalhos do que a qualidade deles propriamente dita. O terceiro parecer é já um franco reparo: "hoje" -a autora escreve, como ficou dito, no início da década de 60- consideram-se "limitadas as suas interpretações históricas", as quais "nem sempre" lhe permitiram aproveitar bem "o vasto material de que se serviu" (265). Ao tentar equilibrar os pontos citados, Maria Antonieta de Azevedo afirma:

O seu inegável mérito foi reconhecido pela Real Sociedade de História de Londres e pela Academia das Ciências de Lisboa, de que foi membro (265).

Enumera ainda a "sua variada e numerosíssima contribuição à historiografia luso-brasileira", a qual, afora os livros já citados, inclui os seguintes:

“Os Jesuitas no Grão-Pará, Lisboa, 1901 (2 $2^{\mathrm{a}}$ ed., Coimbra, 1930). O Marquês de Pombal e a sua época, Lisboa, 1909 (2 ed., emendada, Rio de Janeiro, 1922). A evolução do sebastianismo, Lisboa, 1918. A [sic] História de António Vieira, em 2 volumes, 1918-1921[sic], 2 vols. (2 ${ }^{\mathrm{a}}$ ed., 1931). História dos Cristãos-Novos Portugueses, Lisboa, 1922. (...) Novas Epanáforas. Estudos de História e Literatura [sic], Lisboa, 1932 (Dicionário de História de Portugal 265).

De fato, a relação profunda de João Lúcio de Azevedo com a historiografia brasileira é informação relevante para se compreender o processo retórico de confecção da História de Antônio Vieira. Para começar, em seu prefácio, João Lúcio afirma que foi

... incitado a convertê-la em acto por José Veríssimo, o crítico e poligrafo, de que se honram as letras do Brasil; ajudou-o com atilados conselhos e preciosas indicações Capistrano de Abreu, o cultor exímio da ciência histórica em que é naquele país mestre acatado (Azevedo citação às 8-9).

O diálogo com este último, que em vários momentos refere questões de produção e de recepção da biografia, está em sua maior parte preservado na edição organizada e prefaciada por José Honório Rodrigues da Correspondência de Capistrano de Abreu. Já na introdução do primeiro volume, José Honório observa que a "correspondência entre João Capistrano de Abreu e João Lúcio de Azevedo" havia sido "oferecida à Biblioteca Nacional a 7 de março de 1928 pelo próprio João Lúcio de Azevedo". Escrevia este, quando de sua oferta: 
Por espaço de onze anos tive a fortuna de entreter ativa correspondência com Capistrano de Abreu, e tão interessantes achei suas cartas que as guardei tôdas ou quase tôdas. (...) Pareceu-me por isso que agora, por morte dêle, o lugar adequado para estas cartas seria a Biblioteca Nacional do Rio (...). Ai ficarão sob boa guarda e acessiveis aos amigos e admiradores do finado que, se a família não fizer objeção, as poderão ver, copiar ou publicar, se assim quiserem, porque da minha parte não me oponho a isso (Correspondencia I: IX)

De acordo com José Honório, a correspondência entre os dois historiadores é a "mais volumosa" de todo o livro, "talvez pelo cuidado com que João Lúcio de Azevedo a conservou" (Correspondencia XVIII). E continua: "Onze anos de correspondência erudita, histórica, literária, variada, ligaram o mestre brasileiro ao grande historiador português daquela época" (XVIII). No prefácio ao terceiro volume, José Honório ainda amplifica a declaração:

Nenhuma correspondência tem para os historiadores tanta importância quanto a escrita por João Lúcio de Azevedo, pois estende-se de 1916 a 1927 e trata das pesquisas e das obras que ambos andavam fazendo (III: II-XIII).

Por ora, a respeito dessa correspondência, é quanto basta. A tarefa que me cabe aqui, e da qual não quero me desviar, é examinar os procedimentos retóricos aplicados por João Lúcio de Azevedo em sua biografia do Padre Vieira. Para que isso seja possível, será preciso considerar, por um momento, qual era a situação biográfica de Vieira antes dele.

Entre as principais biografias de Antônio Vieira, a contar do panegírico fúnebre escrito pelo Padre João Antônio Andreoni, Reitor do Colégio da Companhia de Jesus na Bahia, em 20 de julho de 1697, dando conta da morte de Vieira e referindo alguns dos principais feitos de sua vida, estão as seguintes: Vida do Apostólico Padre Antonio Vieira, da Companhia de Jesus, chamado por antonomásia o grande, Lisboa, do jesuíta André de Barros (Officina Sylviana, 1746); Discurso histórico e crítico acerca do Padre Antônio Vieira e das suas obras, de Francisco Alexandre Lobo (Coimbra: Imprensa da Universidade, 1823); Vieira, sa vie et ses oeuvres, de E. Carel (Paris: Gaume et Cie., 
1879); Vida do Padre Antonio Vieira, de João Francisco Lisboa (Lisboa: Typ. Mattos Moreira \& Pinheiro, 1901); História de Antonio Vieira, com factos e documentos novos, de João Lúcio de Azevedo (Lisboa: Clássica, 1918-1920, em 2 vol.); Padre António Vieira, de Hernâni Cidade (Lisboa: Agência Geral das Colônias, 1940); A great luso-brazilian figure: Padre António Vieira, S.J., 1608-1697, de Charles Boxer (London: The Hispanic \& Luso-Brazilian Councils, 1957); Padre António Vieira, de João Mendes (Lisboa Verbo, 1972); António Vieira: o homem, a obra, as idéias, de José Van den Besselaar (Lisboa: ICLP, 1981).

De todas essas biografias, como ficou dito, a História de Antonio Vieira, de João Lúcio, é a melhor documentada e a mais influente produzida até hoje. Afora a primeira, de André de Barros, nenhuma outra se compara a ela como incursão na vida do jesuíta. Mas, claro, a de André de Barros, também da Companhia de Jesus, escrita em período próximo ao da morte de Vieira, tem um escopo inteiramente diverso: edificante, encomiástico e panegírico, e não analítico ou documental. Isto não significa que a História..., de Azevedo, seja definitiva, ou que tenha resolvido todas as questões da vida e obra de Vieira. Trata-se de um relato historiográfico muito eficaz, o que se prova amplamente com a naturalização do retrato que produziu, mas é evidente que não se trata de nenhuma verdade factual revelada e narrada por vontade dos próprios fatos. Já mencionei, por exemplo, que as divisões periodológicas que o historiador português imprime ao relato são convincentes e duradouras, mas, a meu ver, precisam receber revisões mais integradoras.

De qualquer modo, mesmo protestando modéstia, o próprio Azevedo, na Explicação Prévia da primeira edição de sua História de Antonio Vieira, acentua aspectos que considera meritórios em sua biografia, a saber:

a) uma posição que supõe imparcial, ou, como ele diz, sem "achaque de parcialidade" (Azevedo História de Antônio Vieira I:7), nem favorável, como a de André de Barros, "religioso, que de outro religioso, seu consócio, escrevia" (I:7), nem contrária, como ocorre na biografia de João Francisco Lisboa;

b) o aspecto não condensado de sua história em oposição à "memória histórica", como a que produziu o Bispo de Viseu, aspecto que lhe permitia vista mais larga e tempo mais dilatado para a exploração documental;

c) a vasta e inédita documentação, oriunda de diferentes acervos e arquivos; 
d) uma nova maneira de "considerar o sentido dos acontecimentos" (I:8), que ele supunha facultada tanto pela multidão de novos documentos que localizara, e que assim lhe permitiria maior certeza dos fatos, quanto pelo método "crítico", que já não se contentava com a anotação simples do fato, mas buscava uma compreensão mais complexa dele em função da complexidade de seus agentes históricos;

e) a "ausência de toda a pretensão literária" (I:8), e o que supunha ser o desaparecimento da "personalidade do narrador" em favor da "expressão da verdade" (I:8), que lhe permitiria "retratar com alguma fidelidade" a "grande figura" (I:8) de Vieira.

A rigor, entretanto, a não ser no tocante ao critério de ampla investigação documental, todos os outros pontos podem ser facilmente relativizados no tocante a História de Antônio Vieira. Assim, primeiro, se não resta dúvida sobre o desejo de isenção de João Lúcio de Azevedo face aos compromissos mais diretamente religiosos ou institucionais, evidentemente não há, nem pode haver neutralidade decorrente desse desejo, dado que ele próprio se encontra posicionado no campo historiográfico. Mais acertado seria dizer que Azevedo se esforça para que seus instrumentos retóricos demonstrem que é verossímil o Vieira que ele imagina verdadeiro. É evidente, de resto, que a história que produz é toda ela muito argumentativa.

Segundo ponto a destacar: o método historiográfico chamado "crítico" que adquire de suas leituras germânicas (Niebuhr, Ranke etc.), assim como aguça a interpretação do fato, também o psicologiza seguidamente, nem sempre com instrumentos adequados.

Terceiro ponto: a ausência de qualquer pretensão literária, nem é preciso dizer, não passa de aplicação adequada da tópica retórica da modéstia afetada. O seu gosto pelo idioma e a sua preocupação com as questões de elocução são permanentes ao longo deste livro e de todos os outros que escreveu. Por outro lado, não convém esquecer que "pretensão literária", no conjunto da conversa travada entre os historiadores do período, é também referência pejorativa a trabalhos com defeito de documentação, que se disfarçam com a estilização ornada, querendo passar o gato do enfeite esvaziado pela precariedade da lebre informativa.

Se tais observações, como disse, relativizam os argumentos de João Lúcio, de modo algum relativizam a qualidade de seu trabalho biográfico, nem fazem com que perca a sua singularidade em meio aos demais estudos 
vieirianos. Além do esforço principal de busca arquivística e documental, é notável o conjunto de procedimentos retóricos de que lança mão para compor a sua biografia do padre.

Apresento a seguir os principais deles, detendo-me exclusivamente em passos do primeiro e do segundo períodos da divisão estabelecida pela biografia, a fim de não tornar demasiado prolixa a exemplificação.

\section{A. ProposiçÃo de origem}

Em muitos lugares, a História de Antonio Vieira pretende estabelecer uma espécie de origem particular, bem marcada, para certas constantes da ação de Vieira. O efeito desse procedimento é duplo: de um lado, gera um horizonte teleológico para os acontecimentos narrados, já que eles deixam de ser apenas referência a um determinado momento histórico para ganhar foro de anúncio ou explicação de um viés da vida de Vieira que se sedimentará posteriormente. De outro, tende a formular inícios marcantes, algumas vezes traumáticos, para as ações correntes posteriores. O duplo efeito, em conjunto, tende a dramatizar a narrativa, de modo que eventos aparentemente simples se tornam cenas ou matrizes originais de futuras ações importantes.

Por exemplo, João Lúcio afirma que a "impressão profunda" dos tempos de noviço, "jamais havia de se apagar" (Azevedo 17), e que "não admira impressionarem-se com isso as imaginações juvenis" (19). Em outro lance, referindo-se ainda a um Vieira muito jovem, diz: "Acaso data daí o seu interesse pela política" (35). Em outra ocasião, ao comentar o jovem padre que prega na Bahia contra os holandeses, muito distante ainda do embaixador extraordinário que seria das futuras negociações pela paz de Holanda, anota surpreendentemente: "Sem dúvida o primeiro germe do célebre Papel forte de 1648 lhe surdiu então no cérebro" (41). Ou então, quando anuncia como coisa certa o momento em que Vieira caiu nas graças do rei: "Na audiência, que foi a 30 de Abril, começou de nascer a afeição de D. João IV" (48).

\section{B. COMPOSIÇÃO DE LUGAR OU AMBIENTE PRÓPRIO}

Outro procedimento constante empregado por João Lúcio de Azevedo na construção retórica da biografia é a tentativa, referida explicitamente na correspondência que manteve com Capistrano de Abreu, de recriação dos ambientes frequentados pelo biografado. Muitas vezes, as situações vividas por Vieira, como as do noviciado, ou a passagem pelas diferentes cortes 
europeias, entre outras, são destacadas de modo a fazê-las dotadas de um espírito próprio, marcante, cujo contato é sempre impressionante para o neófito.

De certa maneira, trata-se de um procedimento afim ao primeiro, uma vez que acentua um marco de origem, mas aqui ele é menos relativo a um acontecimento do que a meios sociais tratados como ordens fechadas nelas mesmas, e, por isso mesmo, como que imantados por uma grande "tensão moral". Tudo que é próprio da Companhia de Jesus, por exemplo, recebe esse tipo de eletricidade. Falando da prática dos exercícios espirituais, João Lúcio não se contenta em referir o texto ou a estrutura dos exercícios, mas acentua o conjunto dos efeitos que o ambiente produz: "O período é de extraordinária tensão moral para todos" (Azevedo 21); ou então: "Todos os sentidos toca a alucinação; nem uma só corda do instrumento humano que não vibre" (23).

Também Portugal, ou a nação portuguesa, muitas vezes, ganha esse estatuto de ambiente com vontade própria. Referindo, por exemplo, a expectativa geral no país de que surgisse um rei que os livrasse do domínio espanhol, a própria enumeração é eloquente dessa vontade que penetra a tudo e todos:

De quando em quando vinha um caso prodigioso confirmar essas esperanças. Na praia de Sesimbra encontravam-se pedras misteriosas trazidas pelo mar, nas quais se lia claramente a palavra duque: modo de apontar o céu ao povo quem seria o redentor. Em Lamego um louco desatava aos brados de Viva el-rei D. João!.. (Azevedo 59).

As instituições em geral, com base nesse tipo de construção discursiva, jamais são apenas estruturas, hierarquias e conjunto de funções impessoais: isso tudo ganha vida orgânica com uma "mentalidade" própria. Desse ponto de vista, a "mentalidade" jesuítica é um agente constante na biografia: "(...) prodigalizando a lógica das disputas da escola, que é a força motriz do cérebro jesuíta" (Azevedo 61); ou: “(...) nos familiarizemos com tais recantos deste intelecto singular" (61); ou ainda: "[Em Paris] Passava-lhe o mundo diante sem que seus olhos vissem dele mais que o ponto em que havia fitado o pensamento" (84), o que se explicava pela "mentalidade" que lhe fora incutida desde cedo:

Tenha-se por plausivel que seu espírito, formado na rígida disciplina jesuitica, possuía capacidade de abstração maravilhosa. Seguia a sua idéia, desinteressado do mundo que o rodeava, e bastando-lhe a vida interior (Azevedo 102). 
Ou ainda:

(...) por muito apartado que ele andasse da verdadeira observância quanto à disciplina, o seu afecto à Companhia é certíssimo. Amava-a como filho extremoso, com gratidão e ternura; dedicava-lhe as suas ambições e os seus êxitos; e prezava as satisfações do amor-próprio igualmente que por si como glória para ela (Azevedo 138).

E se o meio institucional, na biografia, é animado de uma mentalidade marcante, o outro lado dessa mentalidade recai sobre o impacto profundo que ela provoca sobre as consciências individuais frágeis e sempre muito impressionáveis dos homens do tempo:

O mundo novo em que chegando à corte entrara tinha-o deslumbrado, e o fazia viver como em sonho, esquecido das virtudes do cenóbio, da humildade, da modéstia, do silêncio, tão recomendado pelos ascetas; algumas vezes também acaso da oração (Azevedo 74).

\section{Confronto de tipos e de mentalidades}

Por vezes, João Lúcio tem gosto em produzir situações nas quais as mentalidades que chamei de imantadas são postas em confronto para explicar o que se passa entre os indivíduos. Isto é, o historiador constitui uma espécie de ágon ou disputa entre duas figuras que, a dizer como ele, possuem 'estruturas mentais' distintas. Por exemplo, a disputa entre Portugal, dotado de uma vontade nacional autonomista, e o Padre Vieira, definitivamente apegado a seus próprios arrazoados escolásticos, desassistido de uma real compreensão do ambiente onde os produzia:

O Papel forte descambava afinal em arrazoado inane, e a magia da argumentação sólida perdia o condão ante a vontade nacional manifestada com vigor... (Azevedo 130).

$\mathrm{Ou}:$

A quem lhe estranhasse o desapego da ideia fundamental, de autonomia completa, com que através dos séculos tem persistido a nacionalidade... (Azevedo 144); 
ou ainda:

Aqui fica o capcioso argumentador, e não diz como por tal a autonomia do país integrado de novo na vasta monarquia espanhola se assegurava e a espinha se retirava da garganta dos portugueses (Azevedo 144).

\section{DivisÃo ETAPISTA E DISPOSIÇ̃̃o CAUSAL COM PERIPÉCIAS}

Já mencionei os períodos biográfico-psicológicos, em seis etapas, nos quais João Lúcio de Azevedo dispõe a longa vida de Vieira, referindo-se distintamente a "o religioso"; "o político"; "o missionário"; "o vidente"; "o revoltado"; "o vencido". O efeito desse etapismo é, em certa medida, estancar aspectos que se apresentam entrelaçados no conjunto de sua vida, como política, missionarismo e profetismo, afora dar um tom melancólicopatético ao período final de sua vida na Bahia. A vantagem que ele extrai dessa segmentação é o estabelecimento de uma diretriz dominante a organizar o conjunto da ação de Vieira em intervalos menores e mais concentrados. Quer dizer, por meio desse artifício, estabelece um princípio de economia entre a multidão dos dados.

Ademais, na mesma direção desse esforço de segmentação e ordenação dos acontecimentos, Azevedo procede a operações análogas no interior de cada um dos períodos propostos. Em particular, tende a definir uma espécie de móvel único ou principal para ações bem variadas, de tal modo que tudo o mais (que a própria divisão não contempla) aparece como esquecido por um temperamento volúvel ou excessivamente caprichoso. Por exemplo, ele diz: “... o norte de sua razão era a política. Todo o seu pensar ia aos negócios de Estado" (Azevedo 74); ou então:

Em todo este periodo só o vemos ocupado na política, e só a política o domina. Que tempo lhe restaria para os estudos, para o ensino, para o mister de confessor, objectos primaciais da actividade do jesuita? (Azevedo 96).

Dentro da mesma perspectiva de subordinação de todos os atos de cada período a um único móvel dominante, João Lúcio é obrigado a considerar que Vieira passa por diferentes e radicais transições de um período a outro. Isto é, a aplicação da figura dominante, obriga-o a entender as mudanças como sucessivas peripécias: 
... a transição dera-se já. Volvia-se o político religioso outra vez, mas não deixava de atacar os adversários de antes... (Azevedo 150-51).

E. Biografia como autobiografia: narrativa como autópsia

Outro procedimento decisivo na caracterização da biografia de João Lúcio é dar-lhe forma ou aparência de autobiografia, com a sistemática introdução de escritos do próprio Antonio Vieira em meio à narrativa-, em particular, de trechos dos sermões. Outras vezes, os sermões não são diretamente citados, mas sim parafraseados pela narrativa, como ocorre longamente no passo relativo à invasão holandesa, que corre paralelo à Carta Ânua (Azevedo 27). O artifício permite a João Lúcio introduzir a multidão de papéis que levanta no corpo do relato, sem perda da fluência narrativa, e ainda com o ganho de uma espécie de fiança da fidedignidade do relato, uma vez que se dá em vista do próprio testemunho de Vieira.

\section{F. DistÂNCIA DO BIÓGRAFO EM RELAÇÃO AO BIOGRAFADO}

O testemunho vieiriano não é, entretanto, absoluto. Muitas vezes, João Lúcio submete-o a uma dura avaliação ou processo judicial do qual a palavra do jesuíta sai chamuscada com o veredicto implacável de duvidosa ou mesmo de falsa. Isto é, João Lúcio pretende surpreender no texto de Vieira exageros ou mentiras, cuja denúncia tanto contribui para dar uma imagem do caráter duvidoso do jesuíta como afiança a posição imparcial, ajuizada do biógrafo; por exemplo:

Daqui se vê que exagerava Vieira, mais tarde, dizendo ter D. João $I V$ posto à disposição dele para esta empresa nada menos que 600 mil cruzados. Igual crédito merece a afirmação, no memorial de serviços a D. Pedro II, de lhe ter mandado aquele abonar em Paris, pelo marquês de Niza, 20 mil cruzados para comprar livros. Nem se encontra na correspondência do embaixador indício de que tal fosse ordenado, nem tinha D. João IV inclinação para generosidades semelhantes, e quando as tivesse, não lhas permitiriam na ocasião as circunstâncias do erário (Azevedo 142-43).

Outro exemplo de descrédito do que afirmava Vieira:

É crivel ser tão verdadeira a oferta desta embaixada [em Turim], como a nomeação para suceder na de Sousa Coutinho na Holanda, 
de que igualmente se jactava o padre. Basta reparar em que não teria de se tratar o assunto em Sabóia, mas em Paris, residência do príncipe... (Azevedo 155).

De modo geral, ainda, o biógrafo, escrevendo a partir de uma perspectiva racionalista e pós-positivista, considera tudo o que diz respeito a profetas e profetismos como um tipo de produção intelectual que se deixa corromper pela fantasia, e não hesita em censurá-la: "Desde aí entrou no caminho que levava ao delírio do Quinto império do mundo e da História do Futuro" (Azevedo 60).

\section{G. Testemunhos E PARÁFrASES DO TEMPO}

A aplicação de figuras de distanciamento da biografia em relação ao herói dela não se faz sem o contraponto interessante de, por vezes, Azevedo aproximar ficticiamente o ponto de vista da enunciação daquele do próprio Vieira ou do que julgava ser a "mentalidade" das pessoas ou do tempo em questão. O caso do "estalo" é especialmente interessante. Não apenas porque não é questionado enquanto acontecimento verídico, mas apenas transferido da esfera mística em que o inventara André de Barros para outra basicamente fisiológico-moral, como também porque João Lúcio tende a dramatizar o caso como se ele, narrador, fosse uma testemunha viva dos supostos milagres ocorridos a Vieira. Por exemplo:

Como só recurso encomendou-se ao anjo da guarda, e com poucas passadas, eis lhe salta da escuridão um menino envolto em luz... (Azevedo 18).

Outro exemplo, ainda sobre o estalo:

É de imaginar que orando à Virgem das Maravilhas lhe suplicasse a de o tornar mais hábil para os estudos. Em um de tais lances, a meio da súplica, sentiu como estalar qualquer coisa no cérebro, com uma dor vivissima, e pensou que morria; logo o que lhe parecia obscuro e inacessivel à memória, na lição que ia dar, se lhe volveu lúcido e fixo na retentiva. Dera-se-lhe na mente uma transformação de que tinha consciência. Chegado às classes pediu que o deixassem argumentar, e com pasmo dos mestres venceu a todos os condiscípulos. Daí por diante foi ele o primeiro e mais distinto em todas as disciplinas. Refere o caso o padre André de Barros, de uma testemunha que o 
ouviu de Vieira; este se isso contava aos contemporâneos, não deixou em escrito conhecido, memória de um acontecimento, de que seria interessante encontrar a explicação na fisiologia (Azevedo 16).

O mesmo procedimento de produzir uma paráfrase dramática do acontecimento suposto para depois reclamar uma explicação naturalista dele, João Lúcio utiliza em relação aos inúmeros achaques alegados pelo próprio Vieira, muitas vezes, tendo o jesuíta manifesto interesse de tergiversação ou de encarecimento de sua situação. João Lúcio, desta vez sem contestar a veracidade do alegado, trata de amplificar o dramático e o interpretar como caso de fisiologia natural ou nervosa:

A saúde dele era delicada: o trabalho excessivo e a paixão com que se dava todo aos objectos em que se empregava sacudiam-lhe o organismo, imensamente vibrátil, e o prostravam extenuado" (Azevedo 18).

Ou ainda:

A cada passo caía em cama, deitava sangue pela boca; mas tão robusta era a constituição no fundo, que resistia a isso e ao tratamento brutal das sangrias, a esmo aplicadas, e o pôde levar aos 90 anos, activo de corpo, escorreito de intelecto, e como na quadra juvenil ardido e pugnaz (125).

\section{H. DRAMATIS PERSONAE OU COMPOSIÇÃO DAS PERSONAGENS}

Outro aspecto importante da retórica biográfica de João Lúcio de Azevedo é o que na correspondência com Capistrano mais se discute: a "psicologia do biografado". Não é um ponto simples. É preciso entender mais precisamente que tipo de psicologia interessa à biografia daquele momento histórico, e, sobretudo, o papel que ela cumpre na construção do crível historiográfico que está em jogo aqui.

Em primeiro lugar, é correto dizer que a documentação que permite alguma ilação desse tipo sempre é valorizada por João Lúcio. Isto fica claro quando diz, por exemplo: “(...) no discurso avulta uma nota de interesse para a psicologia do orador" (Azevedo 39). Mas convém perceber logo que a "psicologia", em muitos casos, tem o sentido de composição de um "retrato moral", próximo por vezes do que era costume nas letras seiscentistas e neoclássicas. É o que se lê, por exemplo, nos seguintes passos: 
Tão alto [quanto o das virtudes sublimes] não subiu Vieira; nunca porém em toda a sua longa existência deixou de ser honrado e recto, por o terem mestres e superiores julgado hábil para ensinar, aos que vinham depois dele, essas condenadas doutrinas [casuistas]. Fraquejou, é certo, na caridade com o próximo e no desprezo das injúrias; de versátil pode ser increpado; e algumas vezes o acharemos, por orgulho, em conflito com a verdade. Isso era questão de temperamento e não de teorias...(Azevedo 33);

O carácter impetuoso de Vieira, seu patriotismo ardente, seu zelo de católico fervido, não lhe consentiam manter-se fora das batalhas (35).

Em descrições desse tipo, é bem marcante a pintura de "caráter" ou "temperamento", onde importa muito mais a determinação de paixões e humores típicos que os móveis inconscientes ou profundos. Apesar de ser rigorosamente contemporâneo de Freud, Azevedo passa batido pelas categorias psicanalíticas e lida com traços de uma espécie de fisiologia moralizante. Eis mais alguns rápidos exemplos interessantes:

... a vaidade era um dos seus muitos pontos fracos; mas é certo que ele nas prosopopéias traduzia um sentimento íntimo, profundo e verdadeiro, que tinha em comum com os ouvintes, o amor da terra e da raça, que por sua vez falava em tom estranho e audaz... (41);

A quem estuda a pessoa moral de Vieira mais do que os seus dotes literários, não passará despercebido...(43);

Suposto o feitio de Vieira, seu arrojo natural, sua loquacidade, o apreço em que tinha a própria pessoa, não será temerário imaginar que logo tomou a palavra, e que esta, fluente e persuasiva, cativou com seu encanto o monarca (48);

Lançou-se ardidamente na luta com o ímpeto do seu gênio batalhador.. (68-69);

... a vaidade que foi sempre achaque seu...(72);

(...) otimista como sempre, pelo sestro de não ter em conta os obstáculos, via ele já luzir a decisão final (109).

Para João Lúcio, a "imaginativa", "a paixão", "a fantasia", “a retórica" de Antonio Vieira são tudo formas afetivas similares de um buliçoso moral, em larga medida formado pelo caráter da própria Companhia de Jesus, em parte 
pelo "gênio" inato do autor. É irresistível citar alguns passos muito reveladores de sua forma de conceber o complexo psico-fisiológico do jesuíta:

O plano encantava-o por singular, arriscado e-o que tanto dizia com a sua compleição mental-adverso ao senso comum (111);

Com a usual facilidade, mal delineado ainda na imaginativa o projecto, já ele o via realizado (118);

...fantasia de um espirito singular e irrequieto, apaixonado mais que reflectido... (119);

... agente em demasia buliçoso, e exorbitante nas iniciativas... (124);

...meras criações da fantasia, artefactos da retórica como os tropos de que adornava os seus discursos... (128);

O esquecer as ofensas não era a sua fundamental virtude. O sacerdote, todavia, tinha de o recomendar. Quanto a si, não o cumprindo, se bem que não podia dizê-lo, mostrava o desdém que sentia aos inimigos, e como folgava de os ter, cônscio de que era isso tributo pago à sua valia...(134);

....de nenhum modo em harmonia com o assunto aparente dos escrúpulos de consciência, que servia de pretexto, e através do qual, em chispas, transpareciam remoques fulmíneos; o apaixonado do ataque; o desprezo absoluto dos riscos... (135);

Assim entre a cólera e a resignação súplice flutuava como todas as afeições traídas. No fim vencia o despeito... (154).

\section{COMPOSIÇÃO DE RETRATOS MORAIS}

Já pelas citações anteriores, é fácil perceber que aquilo que Azevedo chama de "psicologia" talvez se traduza melhor pelo que refere também como "pessoa moral", aspecto que não deixa de dar traço arcaizante a sua concepção de Psicologia. Como disse, ele a entende de maneira muito mais próxima à composição perspicaz e aguda do "retrato" do que de qualquer análise da personalidade com base em categorias psíquicas, então em grande desenvolvimento.

Como procedimento argumentativo, distingo-o aqui do anterior apenas pela disposição particular de, em determinados momentos, e com personagens destacadas de sua história, o historiador sustar a via narrativa e preparar- 
se denodadamente para uma composição acabada, lapidar dessas figuras proeminentes. De todos os exemplos que poderia levantar aqui, nenhum ultrapassa em interesse a composição de caráter que o historiador faz do próprio Padre Antonio Vieira, talvez o passo mais conhecido e referido de toda a biografia. Como se costuma dizer, a citação é longa-, mas quebrá-la não seria justo com o rasgo estilístico do biógrafo, quando se encontra cara a cara com seu herói:

Alto e de porte majestoso; na tez o moreno peninsular carregado de um golpe, já distante, do sangue de África; cabelos abundantes e negros, levemente crespos, e um tanto em desalinho. A barba, se já então a usava toda, como quando missionário, espessa e curta, só porém no contorno das faces até o mento, deixando o rosto limpo, menos o bigode caído nas pontas a um e outro lado; assim a máscara nada perdia da expressão, e mais brilhavam abaixo da fronte, maior que um terço do rosto, os olhos grandes, vivissimos e em que a espaços um lance da pupila, distante e vago, traía o sonhador. A boca engraçada, fácil ao sorriso que cativa ou malicioso; com um metal de voz rico de inflexões, que abrangia roda a escala da sensibilidade humana; soando ora arrebatada e vibrante, ora insinuante e meiga; grave, persuasiva, suplicante, irônica, piedosa, conforme a natureza do discurso. Acaso também uma ponta do sotaque, que já nesse tempo adoçaria a fala do Brasil; pela novidade um atrativo mais. Compleição de artista hábil em penetrar a vida secreta do vocábulo, erudição vasta, magnetismo pessoal, talento de atrair de dominar, tudo que dele podia fazer um orador raro e triunfador. Tudo menos a emoção sincera e espontânea; e por isso deleita, prende, convence, deslumbra, mas não enternece nunca nem verdadeiramente arrebata. Só quando perora em causa própria lhe sai da alma a cólera ou o despeito. No mais é um retórico exímio na sua arte, e não um apóstolo incendido em fervor (Azevedo 61-62).

Uma composição desse teor está a um passo de fazer com que o juízo moral do retratado se estenda também à gente do seu tempo. E Azevedo não tarda $\mathrm{a}$ dá-lo, juntando Vieira e os ouvintes agudos numa só feição de época, concebida com base num viés ilustrado, que via já os hábitos e práticas seiscentistas com distância, e mesmo com algum desagrado e descaso:

Também os ouvintes não lhe pediam emoções vivas; o gozo provinhalhes da novidade dos conceitos e da surpresa da combinação verbal. Iam, como ele diz, a "ouvir subtilezas, a esperar galantarias, a avaliar 
pensamentos"; e era o que, embora proteste o contrário, lisonjeava o pregador. Por isso, a tais ouvintes -os de sentimento agudo de que dizia não gostar-prodigalizava subtilezas, galantarias e finos pensamentos. No sério da doutrina falava o moralista e o sacerdote; era a obrigação; no lavor subtil da idéia exibia-se o literato insigne, e isso era o prazer (62)

E não para aí esse tipo de retrato moral: se de Vieira o biógrafo passa rapidamente ao juízo de seu público e mesmo ao juízo de toda uma época, de ambos facilmente passa a uma avaliação estilística dos sermões:

O elevado do seu [discurso] era de bom quilate, e mesmo quando atingia os cumes da eloqüência nunca usou das galas da palavra de modo a sair-lhe velada a nitidez do pensamento. Acaso se lhe pode exprobar algumas vezes o decair no rasteiro; ai o satírico, entregue à sua paixão, olvida um tanto o decoro da tribuna sagrada, Mas estava dentro da arte, e do natural que ele não queria como os culteranistas encontrar; e se as facécias deleitavam ou confundiam, que era ofim procurado, não vinham por elas sacrificadas as regras da boa oratória (62-63).

É certo que João Lúcio lê com estreiteza a censura de Vieira aos culteranos, assim como a sua defesa de um estilo "natural", pois, para o jesuíta, a idéia de "natureza" ajustava-se antes à de natureza cristã, efeito da criação e do engenho divino, que à de clareza ou à condenação do artifício engenhoso nele mesmo. O decoro de púlpito, ainda que prescrevesse arte ou naturalidade, prescrevia antes e primeiramente o ajuste à finalidade cristã da prédica. De modo que, havendo esta, o estilo era sempre adequado e natural.

Mas não é apenas no retrato de Vieira que João Lúcio se esmera. Ocorrem vários outros retratos na biografia, nos quais igualmente se percebe o quanto sua ideia de historiografia se liga mais à composição do caráter dos grandes do tempo que à investigação dos processos históricos de base - aspecto certamente implícito no reparo de "não ter ido além da linha tradicional da historiografia do século XIX", tal como se lê no interior do verbete sobre João Lúcio, no Dicionário de História de Portugal, que citei anteriormente.

No entanto, o talento literário de João Lúcio de Azevedo, se não elimina o reparo historiográfico, faz com que a leitura da biografia, como um todo, ganhe em interesse, e mesmo em atualidade. Quando o texto alcança seu melhor grau de efetuação retórica, o leitor se depara com uma admirável galeria de 
retratos morais, que enquadra um movimentado romance de intriga política, de feição naturalista, que a João Lúcio agradaria conceber como um estilo próprio do "realismo crítico" historiográfico. Entre tantos retratos, avulta, por exemplo, o de D. João IV:

No caráter do rei havia todos os defeitos dos tíbios. Era, como várias vezes mostrou, pusilânime, ingrato, vingativo e, na hora da vingança, cruel. Fácil de dominar, tinha com a plasticidade a inconstância que arrastava a catástrofes súbitas o valido (Azevedo 53).

Não menos interessante é a pintura da Grande Mademoiselle, que a Corte chegou empenhadamente a cogitar como esposa para D. Teodósio, contra a opinião de Vieira:

Mais velha sete anos que o principe, alta em demasia -por tal lhe chamavam a Grande Mademoiselle- robusta e de voz grossa, desleixada no trajar, nos modos e na resolução uma virago, tal era a rainha destinada aos Portugueses (99).

Da mesma qualidade é o esboço do embaixador, correspondente e amigo de Vieira, D. Francisco de Sousa Coutinho:

Foi este uma das mais interessantes personalidades da Restauração, e à luz dos documentos realiza bem o tipo de português antigo, brusco de modos, solto no falar, impetuoso, valente, chalaceador e astuto. Com o rei, a quem servira desde que era ainda Duque de Bragança. Tinha liberdades de criado velho, certo de lhas não tomarem a mal; discutia as ordens, desobedecia, ralhava, escrevia com rude franqueza, a queixar-se, a dar conselhos, a repreender (108).

A composição desses retratos morais particulares algumas vezes se combina com o procedimento, já destacado, de produzir confronto entre mentalidades agônicas. Nesses momentos, a narração conflui para um verdadeiro duelo de caracteres entre pessoas, ou entre pessoas e instituições. É este embate dramático que parece interpretar, a quente, em primeira mão, os movimentos sucessivos da história:

Seu espirito [de Vieira], em moção perpétua, turbulento e dominador, em breve submeteu a fraqueza nativa de D. João IV (53); 
$\mathrm{Ou}:$

Coutinho [Francisco de Sousa] pelo desassombro, quase atrevimento que falava e se impunha; Vieira pela sugestão pessoal, própria dos oradores de lei, pela verbosidade que entontecia e quase lançava em hipnose o lento D. João IV (54).

São dois exemplos menores, entre dezenas de outros de mesmo teor nos quais as personalidades dos grandes se batem entre si e determinam por si mesmos os rumos da história.

Em resumo e para finalizar de maneira mais abrupta e parcial do que seria conveniente: boa parte dos procedimentos retóricos aqui relacionados deixa claro que, seja pela invenção dramática, pelo apuro estilístico ou pela disposição cuidadosamente prevista -bem diversamente do que ele alega- ao biógrafo João Lúcio de Azevedo nunca lhe faltou pulso nem gosto para o desenho vivo do biografado morto.

Ao empregar, porém, esse vasto leque de recursos retóricos, João Lúcio mantém sempre firme a preocupação de apagamento da habilidade de desenhista. Para que, ao fim e ao cabo, após a aplicação de uma meticulosa arte de esconder a arte, como que desaparecesse o biógrafo -- e o biografado se deixasse naturalmente contar pelo legado quase intocado de seus papéis. Qualquer coisa parecida com o que, em nossos dias, se poderia chamar de "Vieira por ele mesmo".

Como se o acerto da biografia residisse na habilidade retórica para apresentá-la ao público com a face histórica limpa de retórica. E não será fácil desmenti-lo, uma vez que "História de Antônio Vieira" é um caso de êxito duradouro.

\section{BIBLIOGRAFIA}

Abreu, Capistrano de. Correspondência de Capistrano de Abreu. Prefacio de José Honório

Rodrigues. Rio de Janeiro: Instituto Nacional do Livro, 1954-56, em três volumes. Azevedo, João Lúcio de. História de Antônio Vieira. Clássica Editora, $3^{\text {a }}$ ed., 1992. 
Buarque de Holanda, Sérgio. Perspectivas. Organização de Pedro Meira Monteiro e João Kennedy Eugênio. SP/RJ: Editora da Unicamp/ eduerj, 2008.

Dicionário de História de Portugal, dirigido por Joel Serrão. Iniciativas Editoriais, 1963. 